\title{
Prevalence of erectile dysfunction oral drugs use in a city of southern Brazil
}

\author{
Prevalência do uso de drogas orais para disfunção erétil \\ em uma cidade do sul do Brasil
}

\author{
Daniel Vanti Duarte ${ }^{1}$ \\ María Clara Restrepo-Méndez ${ }^{1}$ \\ Mariângela Freitas da Silveira ${ }^{1}$
}

${ }^{1}$ Departamento MaternoInfantil, Faculdade de Medicina, Universidade Federal de Pelotas. Av. Duque de Caxias 250, Fragata. 96030-001 Pelotas RS Brasil.

dvduarte@hotmail.com

\begin{abstract}
The last decade has seen a breakthrough in the treatment of erectile dysfunction (ED) with the advent of phosphodiesterase-5 inhibitors. There are few population-based observational studies on the prevalence of use of these drugs. We conducted a cross-sectional population-based study in the city of Pelotas (Brazil). Our sample comprised 1,082 men aged 20 years or older who answered a confidential and self-administered questionnaire. Prevalence of EDD use was 5\% $(I C 95 \%=4 \% ; 7 \%) . E D$ and advanced age were strongly associated with a higher prevalence of $E D D$ use. ED prevalence in men who used EDD was $68 \%$, which was much higher than the one found in the entire sample (27\%). The use of EDD was more frequently reported among separated men, respondents with higher level of education and those without ED. A high proportion of respondents (68\%) did not seek medical advice on the use of EDD. Sildenafil was the most commonly used drug (38\%) but non-regulated and non-evidence-based drugs were also frequently used (14\%). Prevalence of EDD use is higher among individuals with $E D$, opposing to the notion of recreational use of EDD.
\end{abstract}

Key words Erectile dysfunction, Prevalence, Medication, Cross sectional
Resumo Na última década houve um grande avanço no tratamento da disfunção erétil (DE), com o advento dos inibidores da fosfodiesterase-5. Existem poucos trabalhos sobre a prevalência de uso destas drogas. Foi realizado um estudo transversal de base populacional na cidade de Pelotas. A amostra foi composta por 1.082 homens com 20 anos ou mais de idade que responderam um questionário confidencial e auto-aplicado. A prevalência do uso de medicamentos estimulantes da ereção (MEE) foi de 5\%(IC95\% = 4\%-7\%). Idade avançada e DE foram fortemente associados a uma maior prevalência de uso de MEE. A prevalência foi também maior em indivíduos com ensino superior e aqueles separados. A prevalência de DE em homens que usaram MEE foi de 68\%, sendo maior do que a prevalência encontrada em toda a amostra (27\%). A maioria dos indivíduos não teve aconselhamento médico para o uso de MEE (68\%). Sildenafil foi a droga mais utilizada (38\%), seguida por aquelas não regulamentadas (14\%). A prevalência do uso de MEE é maior em indivíduos com disfunção erétil, opondo-se à noção de uso "recreativo" de EDD.

Palavras-chave Disfunção erétil, Prevalência, Medicação, Estudo transversal 


\section{Introduction}

The last decade has seen remarkable advances in the management of erectile dysfunction (ED) with the advent of phosphodiesterase-5 (PDE-5i) inhibitors (sildenafil, tadalafil, vardenafil, lodenafil and udenafil). A review showed that several studies have evidenced the efficacy and safety of these drugs ${ }^{1}$. In the United States, the prevalence of sildenafil use increased from $0.8 \%$ to $1.4 \%$ $(84 \%)$ in the first four years after its introduction to the market ${ }^{2}$. It is estimated a growing use of PDE-5i drugs in Brazil, which trade moves annually more than 70 million dollars with high investment by the pharmaceutical industry. ${ }^{3}$ Furthermore, there is a parallel trade of non-regulated drugs for erectile dysfunction. These drugs have not been approved for use by the Brazilian National Health Surveillance Agency (ANVISA) and are smuggled and sold unlawfully without medical prescription ${ }^{3}$.

The use of PDE-5i drugs has been associated with several adverse effects. These adverse effects are mild, such as facial flushing, headache and nasal congestion. In addition, there are few case reports relating to the use of PDE-5i agents with serious complications, such as myocardial infarction, aortic dissection, stroke, ocular and auditory complications ${ }^{4-6}$. A meta-analysis has showed severe clinical adverse events of PDE-5i drugs are not more common than placebo ${ }^{7}$.

A study conducted in 19 Brazilian cities found that the prevalence of erectile dysfunction was $43.6 \%$ and the proportion of men who reported ever taking a drug of any type to stimulate or maintain an erection was $14.9 \%$. This study interviewed 5,613 men aged 40 years or older recruited in the streets, parks, malls and beaches and used self-administered questionnaire ${ }^{8}$.

Some studies have showed that young adults often use EDD for recreational purposes, associated with alcohol, illicit drugs, multiple sexual partners, unprotected sex and sex with other $m^{9} n^{9,10}$. EDD seem to be obtained with appropriate medical advice in less than $5 \%$ of cases ${ }^{11,12}$.

Despite easy access to EDD in Brazil, there are no population-based studies on the prevalence of EED use and factors associated. The large studies on male sexuality carried out in Brazil have focused mainly on the prevalence of ED and have described briefly the prevalence of $\mathrm{EDD}^{13-16}$. Other studies have focused exclusively on the use of PDE-5i in young adults ${ }^{17,18}$, without exploring other medications used for enhancing erection. Non-regulated 5-IPDE drugs are known to be unlawfully sold in Brazil but the proportion of its users is unknown.

Therefore, we aimed to assess the prevalence of EDD use among adult men, to describe the profile of EDD users and major socioeconomic and behavioral factors associated with their use.

\section{Methods}

We conducted a cross-sectional population-based study in Pelotas, a mid-sized city with approximately 350,000 inhabitants located in southern Brazil. Data was collected from January 25 to May 5, 2010. Random cluster sampling technique was used based on 408 census tracts in the urban area, according to the most recent census of the Brazilian Institute of Geography and Statistics (IBGE). This study is part of a health research consortium that addressed more than 13 topics, and interviewed 3,059 people aged 20 years or older. Sample size estimation was based on a prevalence of EDD use of 3,5\% which was obtained through a pilot study, a confidence interval of $95 \%$, a power of $80 \%$ and a two-tailed test with a $5 \%$ significance level. We also added $15 \%$ to the final sample size to correct for possible losses and refusals and $70 \%$ for design effect. A minimum sample size of 1,458 respondents was required to assess the association of EDD use and sexual orientation. Because we could not interview 1,458 individuals, we could not assess the association between EDD use and sexual orientation. However, the final sample obtained was large enough to assess other associations of interest and the prevalence of EDD use. Trained female interviewers who had completed high school carried out data collection during home visits. The interviewers received a 40 hours training and their performance was evaluated in a pilot study before being selected to the study. Data were collected through a confidential, anonymous, and self-administered questionnaire consisting of nine questions on the use of EDD. Before answering the questionnaire, respondents were informed about anonymity and confidentiality of responses. Men aged 20 years or older were included in the study. We excluded those men illiterate and those who had physical limitations that would prevent completion of the questionnaire. Data quality control was carried out by applying a simplified questionnaire to $10 \%$ of the sample.

Those who agreed to participate in the study received a kit including a copy of the question- 
naire, a clipboard, a pen, an envelope and a stapler. Respondents were asked to complete the questionnaire, place it into the envelope, clip it and drop it in a sealed box. All envelopes were opened only by the principal researcher. These confidential questionnaires were double entered and validated using EpiData. A number on the back of the questionnaire linked the confidential questions to non-confidential information (e.g., income, level of education, age, marital status, etc.). Data entry staff had access only to this number; therefore respondents could not be identified by their names.

The study was approved by the Research Ethics Committee of the Faculty of Medicine of the Federal University of Pelotas.

Erectile dysfunction was evaluated by a single question derived from the Massachusetts Male Aging Study ${ }^{19,20}$ used by Abdo et al in a Brazilian study ${ }^{13}$.

EDD use was defined as having used any substance (PDE-5i, non-regulated drugs or others) in order to stimulate erection, with or without a medical prescription.

Statistical analyses were conducted using STATA 10. We used chi-square tests for bivariate analysis and Poisson regression for multivariable analysis. Adjusted analyses were based on a conceptual model with two hierarchical levels of determination. The first (distal) level included age, marital status, schooling and income; and the second (intermediate) level included degree of self-reported ED. Variables with a level of significance of 0.2 in univariate analyses were kept in the final model. The survey sample design was taken into account in all analyses. We used svyset Stata commands to take into account the sample weights and clustering.

\section{Results}

Of 3,059 eligible individuals for the health research consortium, 1,331 (43.5\%) were male, of which $13.5 \%$ refused to be interviewed or were considered losses to follow up. Of the remaining $1,151,49(4.2 \%)$ were excluded as they were illiterate (41) or not able to complete a self-administered questionnaire (motor sequelae of stroke, dementia and visual disability). The number of households visited was 1,512 and the average of men per household was 0.88 . Of the 1,102 men eligible to complete the confidential questionnaire, $20(0.2 \%)$ were lost or refused to participate. A total of 1,082 men completed the confi- dential questionnaire, of those 58 men reported no sexual intercourse during the last year and were excluded from the analysis. Design effect on the outcome was 1.13. Figure 1 shows losses to follow up and refusals.

Compared to respondents, nonrespondents were significantly older, less educated and had lower income. No difference was found regarding marital status and race.

From a total of 1,082 confidential questionnaires, $71 \%$ were properly filled out. The prevalence of use of EDD during the last year was 5.0\% (95\% CI 3.6\%-6.5\%).

Table 1 describes sociodemographic and behavioral characteristics of the sample. The mean age was 44.4 years (range: $20-88$; standard deviation [SD]: 15.8 years). Approximately $70 \%$ of the respondents were married and $62 \%$ had middle school education. Forty-two percent of respondents were from families in the upper tertile of household income (above 3.5 monthly minimum wages). The Brazilian monthly minimum wages in 2010 was U\$ 356,25. Thirteen respondents (1.3\%) reported ever having sex with other men. Twenty seven percent of individuals of total sample reported to have some degree of erectile dys-

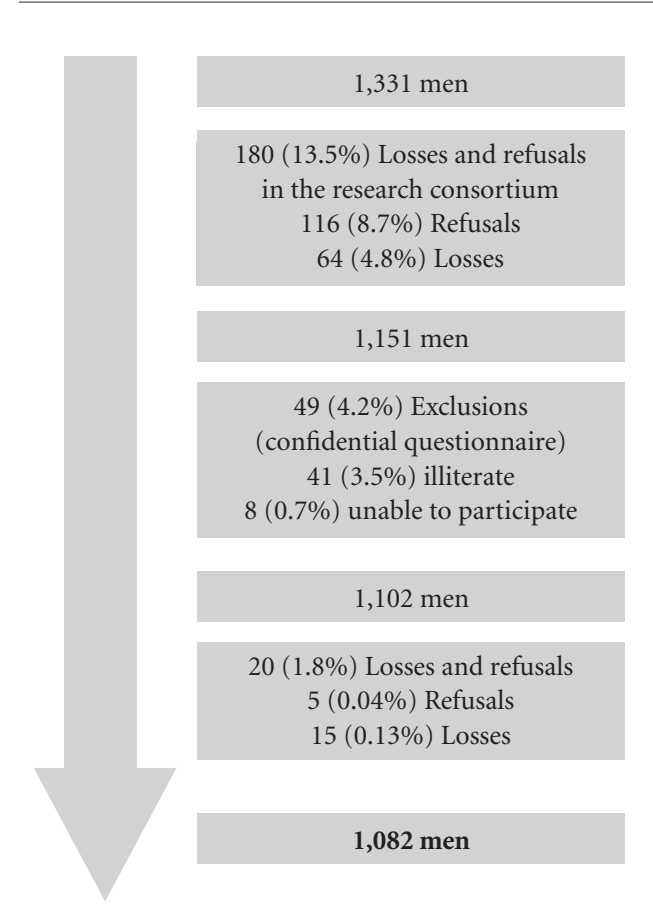

Figure 1. Losses, refusals and exclusions in the confidential questionnaire of the study. 
Table 1. Socio-demographic and behavioral characteristics of male respondents.

\begin{tabular}{|c|c|c|c|}
\hline Variable & $\mathbf{N}$ & Prevalence (\%) & 95\% CI \\
\hline Total & 1082 & 100 & - \\
\hline \multicolumn{4}{|l|}{ Age } \\
\hline $20-29$ & 250 & 23.1 & $20.9-25.3$ \\
\hline $30-39$ & 193 & 17.8 & $15.4-20.2$ \\
\hline $40-49$ & 233 & 21.6 & $19.1-24.0$ \\
\hline $50-59$ & 198 & 18.3 & $16.4-20.2$ \\
\hline 60 or more & 208 & 19.2 & $16.9-21.6$ \\
\hline \multicolumn{4}{|l|}{ Marital status } \\
\hline Married/living with a partner & 735 & 68.0 & $65.0-70.1$ \\
\hline Single/not living with a partner & 255 & 23.6 & $20.1-26.1$ \\
\hline Separated & 64 & 5.9 & $4.5-7.4$ \\
\hline Widowed & 28 & 2.6 & $1.6-3.6$ \\
\hline \multicolumn{4}{|l|}{ Education (years of schooling) } \\
\hline $0-4$ & 193 & 18.1 & $14.8-21.4$ \\
\hline $5-11$ & 665 & 62.4 & $58.8-65.9$ \\
\hline 12 or more & 208 & 19.5 & $15.4-23.6$ \\
\hline \multicolumn{4}{|l|}{ Income (tertiles) } \\
\hline 1 st & 254 & 23.8 & $20.4-27.1$ \\
\hline $2 \mathrm{nd}$ & 365 & 34.2 & $30.5-37.8$ \\
\hline $3 r d$ & 449 & 42.0 & $37.2-46.8$ \\
\hline \multicolumn{4}{|l|}{ Sexual orientation and activity * } \\
\hline Women only & 965 & $93.1 \%$ & 91.6-94.7 \\
\hline Men and women & 13 & $1.3 \%$ & $0.6-1.9$ \\
\hline No sexual relations last year & 58 & $5.6 \%$ & $4.2-7.0$ \\
\hline \multicolumn{4}{|l|}{ Degree of self-reported $\mathrm{ED}^{\dagger}$} \\
\hline No ED & 725 & $73.0 \%$ & $70.3-75.9$ \\
\hline $\mathrm{ED}$ & 267 & $27.0 \%$ & $24.1-29.7$ \\
\hline
\end{tabular}

${ }^{*}$ Missing values $=104 .{ }^{\dagger} \mathrm{ED}$ : erectile dysfunction.

function. The question on sexual orientation had the highest rate of missing information (9.6\%).

Table 2 describes EDD use among individuals with and without erectile dysfunction according to socioeconomic characteristics. The prevalence of EDD use was higher among individuals with ED at all age groups. Among individuals whose marital status is separated, the prevalence of EDD use was not related with ED report, differently from the other categories of marital status that shown higher prevalence of EDD use among those reporting ED. A higher prevalence of EDD use among men reporting ED was found also at all income and schooling groups when compared to those without ED.

Figure 2 shows the most commonly used type of EDD. Among those who reported using EDD during the last year, 38\% used sildenafil, 14\% non-regulated PDE-5i, 12\% other medications such as tonics and vitamins, 10\% tadalafil, 6\% vardenafil and $6 \%$ lodenafil. Fourteen percent of men did not recall the medication used, and $16 \%$ used more than one type of EDD. Most men
(68\%) reported having used EDD without medical supervision. None user younger than 39 years sought medical advice whereas $36.6 \%$ of men older than 39 years sought medical advice $(\mathrm{p}=$ 0.05 )

With regard to motivation for EDD use, about two-thirds reported using them to enhance their sexual performance. However, $75.9 \%$ of men who selected this answer had some degree of ED. Curiosity was the second most reported reason (15.7\%); 10\% admitted that without medication they could not obtain an erection; $7.8 \%$ used for fear of failing erection; and 6\% reported other reasons, including premature ejaculation.

Regarding the frequency of EDD use, $56 \%$ reported occasional use and $22 \%$ reported always or almost always using them when they had sex last year.

Twenty-six percent of respondents reported using EDD with alcohol, and none reported using them with illicit drugs.

Table 3 describes crude and adjusted effects of age, marital status, income, education level, 
Table 2. Distribution of $\mathrm{EDD}^{\star}$ use according socioeconomic variables in individuals with $\mathrm{ED}$ and without $\mathrm{ED}^{\dagger}$.

\begin{tabular}{lcccc}
\hline \multirow{2}{*}{ Variables } & \multicolumn{2}{c}{ Without DE } & \multicolumn{2}{c}{ With DE } \\
\cline { 2 - 5 } & $\mathbf{N}$ & Prevalence (\%) & N & Prevalence (\%) \\
\hline Age & 219 & 0,9 & 18 & 11,1 \\
20-29 & 159 & 3,1 & 22 & 9,1 \\
30-39 & 170 & 1,8 & 39 & 12,8 \\
40-49 & 111 & 1,8 & 38 & 13,2 \\
50-59 & 64 & 6,5 & 40 & 7,5 \\
60 or more & & & & \\
Marital status & 473 & 1,1 & 121 & 9,9 \\
Married/living with a partner & 195 & 2,6 & 24 & 12,5 \\
Single/not living with a partner & 9 & 0 & 4 & 25,0 \\
Widowed & 46 & 13,0 & 8 & 12,5 \\
Separated & & & & \\
Education (years of schooling) & 76 & 1,32 & 34 & 2,9 \\
0-4 & 477 & 1,47 & 87 & 6,9 \\
5-11 & 762 & 4,9 & 35 & 25,7 \\
12 or more & & & & \\
Income (tertiles) & 166 & 1,8 & 34 & 2,9 \\
1st (lowest) & 240 & 1,2 & 46 & 4,3 \\
2nd & 306 & 3,3 & 76 & 17,1 \\
3rd (highest) & & &
\end{tabular}

* Erectile dysfunctions drugs, ${ }^{\dagger}$ Erectile Dysfunction.

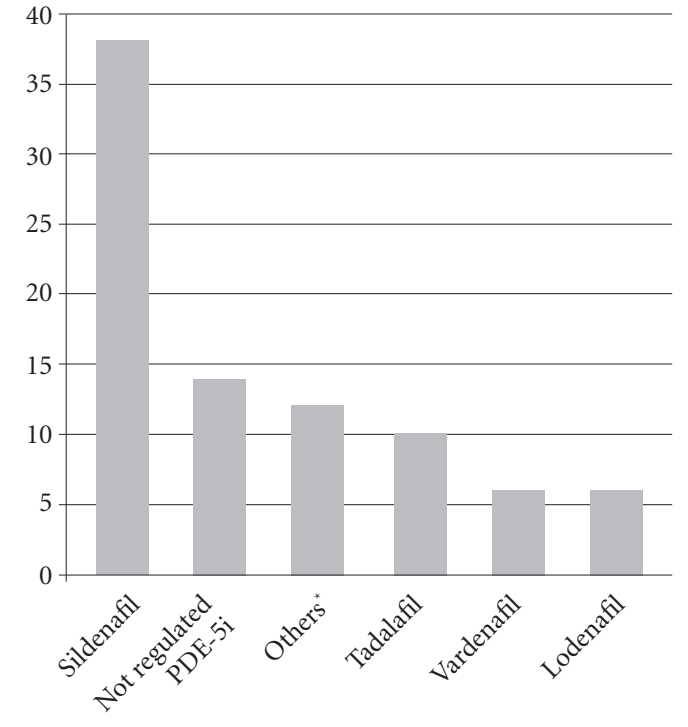

* other medications such as tonics, vitamins and herbal products

Figure 2. Relative frequency of erectile dysfunction drugs use on the last 12 months. Pelotas, Brazil, 2010.

sexual orientation and ED on the prevalence of EDD use. The prevalence of EDD use was higher in respondents with ED compared with those who did not report this condition. This effect remained after adjusting for age, income, education level, marital status and sexual orientation (PR 5.4, 95\% CI 2.8-10.6; $\mathrm{p}<0.001$ ). There was a positive linear trend of age in EDD use $(\mathrm{p}<$ 0.001), with PRs increasing with age and higher ratio among individuals aged 60 years or more (PR 8.0, 95\% CI 2.9-22.1; $\mathrm{p}<0.001$ ). The prevalence of EDD use was higher among separated individuals compared to married or those living with a partner, even after adjusting for confounders (PR 3.3, 95\% CI 1.7-6.3; p < 0.001). In addition, higher education was associated with higher prevalence of EDD $(p<0.001)$. As for household income, no difference in the prevalence of EDD between tertiles of income was found after adjusting for age, education level, marital status, sexual orientation.

\section{Discussion}

The prevalence of EDD use was 5\%. The prevalence of the EDD use was much higher in respondents with some degree of $\mathrm{ED}$, in comparison to individuals without ED. We could not find other population-based studies on the prevalence of EDD use to compare to our findings. The Population-Based Study of the Elderly in Brazil: Men's 
Table 3. Factors associated with erectile dysfunction drugs use in men, according to socio-demographic and behavioral characteristics.

\begin{tabular}{|c|c|c|c|c|c|c|c|}
\hline \multirow[b]{2}{*}{ Variable } & \multirow[b]{2}{*}{ Prevalence (\%) } & \multicolumn{3}{|c|}{ Crude analysis } & \multicolumn{3}{|c|}{ Adjusted analysis } \\
\hline & & $\mathbf{P R}^{*}$ & $95 \% \mathrm{CI}^{\dagger}$ & p-value & $\mathbf{P R}^{*}$ & $95 \% \mathrm{CI}^{\dagger}$ & p-value \\
\hline \multicolumn{8}{|l|}{ Age } \\
\hline $20-29$ & 2.4 & 1.0 & - & & 1.0 & - & \\
\hline $30-39$ & 3.7 & 1.5 & $0.6-4.3$ & $<0.001^{\ddagger}$ & 2.0 & $0.7-5.5$ & $<0.001^{*}$ \\
\hline $40-49$ & 4.4 & 1.8 & $0.7-4.8$ & & 2.9 & $1.1-7.3$ & \\
\hline $50-59$ & 5.3 & 2.2 & $0.8-5.8$ & & 3.1 & $1.1-8.6$ & \\
\hline 60 or more & 10.3 & 4.3 & $1.7-10.1$ & & 8.0 & $2.9-22.1$ & \\
\hline \multicolumn{8}{|l|}{ Marital status } \\
\hline Married/living with a partner & 4.5 & 1.0 & - & & 1.0 & - & \\
\hline Single/not living with a partner & 4.8 & 1.1 & $0.6-2.0$ & $0.03^{\varsigma}$ & 1.9 & $0.9-3.9$ & $0.02^{\S}$ \\
\hline Widowed & 4.1 & 0.9 & $0.1-6.3$ & & 0.7 & $0.1-4.8$ & \\
\hline Separated & 13.0 & 2.9 & $1.4-5.8$ & & 2.6 & $1.4-5.0$ & \\
\hline \multicolumn{8}{|l|}{ Education (years of schooling) } \\
\hline $0-4$ & 1.7 & 1.0 & - & & 1.0 & - & \\
\hline $5-11$ & 4.4 & 2.6 & $0.8-8.3$ & $<0.001^{\ddagger}$ & 3.5 & $1.1-11.3$ & $<0.001^{\ddagger}$ \\
\hline 12 or more & 9.6 & 5.7 & $1.7-18.5$ & & 7.7 & $2.4-24.0$ & \\
\hline \multicolumn{8}{|l|}{ Income (tertiles) } \\
\hline 1st (lowest) & 3.7 & 1.0 & - & & 1.0 & - & \\
\hline 2nd & 2.2 & 0.6 & $0.2-1.6$ & $<0.001^{\ddagger}$ & 0.5 & $0.2-1.3$ & $0.2^{\ddagger}$ \\
\hline 3rd (highest) & 7.9 & 2.1 & $1.0-4.7$ & & 1.5 & $0.6-3.5$ & \\
\hline \multicolumn{8}{|l|}{ Degree of self-reported ED ${ }^{\star *}$} \\
\hline No ED & 2.2 & 1.0 & - & $<0.001^{\S}$ & 1.0 & - & $<0.001^{\S}$ \\
\hline ED & 12.8 & 5.8 & $3.2-10.4$ & & 5.4 & $2.8-10.6$ & \\
\hline
\end{tabular}

${ }^{\star}$ Prevalence ratio. $\uparrow 95 \%$ confidence interval. $\ddagger$ Test for linear trend. $§$ Test for heterogeneity of proportions. ${ }^{\star \star}$ ED: erectile dysfunction.

Results $^{8}$ reported a $14.9 \%$ prevalence of EDD use, however, this study selected a convenience sample. Thus, more than a half of respondents (54.8\%) were college educated.

Sildenafil was the most commonly reported drug. This is possibly due to a longer clinical experience with this drug (about 10 years) and massive advertisement campaigns. Non-regulated PDE-5i were the second most used EED which may reflect their lower cost and ease of purchase without prescription, as well the lack of control of illegal trade of these products. A significant proportion of EDD users made use of several agents simultaneouslysuch as vitamins, tonics, herbal extracts, among others, which have non-evidence-based of their effects.

We observed a discrepancy between ED prevalence and EDD use. This paradox between high prevalence of ED and low EDD use has been previously reported ${ }^{21,22}$ and may be explained to certain extent by age. Age was strongly positive associated with EDD use and higher prevalence of ED, which justifies increased EDD use among older individuals. Otherwise, the prevalence of
EDD use may be underestimated among younger individuals because they may find difficult to admit their use at younger ages.

Prevalence of EDD use was higher among separated men, even after adjusting for age, education, income and sexual orientation. Higher education levels were associated with higher prevalence of EDD use. A high proportion of men reported using EDD with alcohol, but there were no reports of concomitant use of illicit drugs and EDD.

Regarding sexual orientation, the prevalence of respondants who reported ever having sex with other men was $1.3 \%$. This rate is much lower than the one reported on other studies (around $5 \%)^{8,11}$. No significant association was found between sexual orientation and EDD use.

Our study has limitations inherent to studies that address personal, intimate issues or issues that cause social constraints. Despite all our efforts to ensure data protection and confidentiality, respondents may have felt embarrassed to provide accurate answers. The fact that the questionnaires were provided by female interviewers 
during home visits may have caused some constraints and led to an underestimation of prevalence of EDD use. In fact, our study found lower prevalence compare to other studies ${ }^{13}$. We found a prevalence of ED of $27 \%$, which was lower than the ones reported in other Brazilian studies ${ }^{13-15}$ that used the same instrument (40\% to $45 \%$ ). Moreover, the prevalence of men reporting having sex with other men was lower in our study $(1.3 \%)$ in comparison with previous studies (around 5\%) $)^{8,11}$. Another limitation of self-administered studies is that illiterate and functionally illiterate individuals are excluded. Finally, it is important to mention that these results must be interpreted with caution as the data was collected in 2010 and therefore some results may be different from data collected five years later due to changes in behavior over time.

\section{Conclusions}

The prevalence of EDD use in the last year was $5 \%$ (95\% CI 3.6\%-6.5\%). EDD use is strongly associated with ED. The frequency of of EDD use is higher between older men. EDD are primarily used without medical supervision. Individuals who have higher level of education or who are separated seem to use EDD more frequently than those with lower level of education or with other marital status, respectively. A high proportion of men use non-regulated PDE-5i and non-evidence-based EDD.

\section{Collaborators}

DV Duarte: Responsible for conceptualization, coordination of field work and data collection, statistical analyses and writing of original draft of manuscript. MC Restrepo-Mendéz: Responsible for supervision of methodology and formal analyses, and reviewing and editing manuscript. MF Silveira: Responsible for supervision of methodology and validation, and reviewing and editing manuscript. 


\section{References}

1. Campbell HE. Clinical monograph for drug formulary review: erectile dysfunction agents. J Manag Care Pharm 2005; 11(2):151-171.

2. Delate T, Simmons VA, Motheral BR. Patterns of use of sildenafil among commercially insured adults in the United States: 1998-2002. Int J Impot Res 2004; 16(4):313-318.

3. Agencia Nacional de Vigilância Sanitária (Anvisa). [cited 2009 Aug 26]. Available from: http://www.portal. anvisa.gov.br

4. Alpsan MH, Bebek N, Ciftci FD, Coban O, Bahar S, Tuncay R. Intracerebral hemorrhage associated with sildenafil use: a case report. J Neurol 2008; 255(6):932933.

5. Tiryakioglu SK, Tiryakioglu O, Turan T, Kumbay E. Aortic dissection due to sildenafil abuse. Interact Cardiovasc Thorac Surg 2009; 9(1):141-143.

6. Maddox PT, Saunders J, Chandrasekhar SS. Sudden hearing loss from PDE-5 inhibitors: A possible cellular stress etiology. Laryngoscope 2009; 119(8):1586-1589.

7. Tsertsvadze A1, Yazdi F, Fink HA, MacDonald R, Wilt TJ, Bella AJ, Ansari MT, Garritty C, Soares-Weiser K, Daniel R, Sampson M, Moher D. Oral sildenafil citrate (viagra) for erectile dysfunction: a systematic review and meta-analysis of harms. Urology 2009; 74(4):831836.

8. Abdo CHN, Afif-Abdo J. Estudo Populacional do Envelhecimento Brasileiro: Resultados Masculinos. RBM rev. bras. med 2007; 64(8):379-383.

9. Smith KM1, Romanelli F. Recreational Use and Misuse of Phosphodiesterase-5 Inhibitors. J Am Pharm Assoc 2005; 45(1):63-72.

10. Mc Cambridge J, Mitcheson L, Hunt N, Winstock A. The rise of Viagra among British illicit drug users: 5-years survey data. Drug Alcohol Rev 2006; 25(2):111113.

11. Musacchio NS, Hartrich M, Garofalo R. Erectile dysfunction and viagra use: what's up with college-age males? J Adolesc Health 2006; 39(3):452-454.

12. Santtila P, Sandnabba NK, Jern P, Varjonen M, Witting K, von der Pahlen B. Recreational use of erectile dysfunction medication may decrease confidence in ability to gain and hold erections in young males. Int J Impot Res 2007; 19(6):591-596.

13. Abdo CH, Oliveira Júnior WM, Scanavino Mde T, Martins FG. Erectile dysfunction: results of the Brazilian Sexual Life Study. Rev Assoc Med Bras 2006; 52(6):424429.

14. Moreira Júnior ED, Bestane WJ, Bartolo EB, Fittipaldi JA. Prevalence and determinants of erectile dysfunction in Santos, southeastern Brazil. Sao Paulo Med J 2002; 120(2):49-54.
15. Moreira Júnior ED, Lisboa Lobo CF, Villa M, Nicolosi A, Glasser DB. Prevalence and correlates of erectile dysfunction in Salvador, northeastern Brazil: a population-based study. Int J Impot Res 2002; 14(Supl. 2):S3-9.

16. Moreira Junior ED, Brock G, Glasser DB, Nicolosi A, Laumann EO, Paik A, Wang T, Gingell C; GSSAB Investigators' Group. Help-seeking behaviour for sexual problems: the global study of sexual attitudes and behaviors. Int J Clin Pract 2005; 59(1):6-16.

17. Korkes F, Costa-Matos A, Gasperini R, Reginato PV, Perez MD. Recreational use of PDE5 inhibitors by young healthy men: recognizing this issue among medical students. J Sex Med 2008; 5(10):2414-2418.

18. Freitas VM, Menezes FG, Antonialli MMS, Nascimento JWL. Frequência do Uso de Inibidores da Fosfodiesterase-5 por Estudantes Universitários. Rev Saude Publica 2008; 42(5):965-967.

19. Feldman HA, Goldstein I, Hatzichristou DG, Krane RJ, McKinlay JB. Impotence and its medical and psychosocial correlates: results of the Massachusetts Male Aging Study. J Urol 1994; 151(1):54-61.

20. Feldman HA, Goldstein I, Hatzichristou DG, Krane RJ, McKinlay JB. Construction of a surrogate variable for impotence in the Massachusetts Male Aging Study. J Clin Epidemiol 1994; 47(5):457-467.

21. May M, Gralla O, Knoll N, Fenske S, Spivak I, Rönnebeck C, Hoffmann M, Lenk S, Hoschke B. Erectile dysfunction, discrepancy between high prevalence and low utilization of treatment options: results from the 'Cottbus Survey' with 10000 men. BJU Int 2007; 100(5):1110-1115.

22. Rosen RC, Fisher WA, Eardley I, Niederberger C, Nadel A, Sand M; Men's Attitudes to Life Events and Sexuality (MALES) Study. The multinational Men's Attitudes to Life Events and Sexuality (MALES) study: I. Prevalence of erectile dysfunction and related health concerns in the general population. Curr Med Res Opin 2004; 20(5):607-617.

Artigo apresentado em 15/06/2015

Aprovado em 23/03/2016

Versão final apresentada em 25/03/2016 